\title{
A Grounded Theory Approach to Brand Value Networks: The Prosumption Logic Standpoint
}

\author{
Lei Shen, Cuijuan Qin, Chu Luo \\ School of Glorious Sun Management, Donghua University, Shanghai, China \\ Email: slei@dhu.edu.cn, Sunnyqcj@163.com,luochu66@126.com
}

How to cite this paper: Shen, L., Qin, C. J., \& Luo, C. (2020). A Grounded Theory Approach to Brand Value Networks: The Prosumption Logic Standpoint. American Journal of Industrial and Business Management, 10, 841-860.

https://doi.org/10.4236/ajibm.2020.104057

Received: February 5, 2020

Accepted: April 27, 2020

Published: April 30, 2020

Copyright $\odot 2020$ by author(s) and Scientific Research Publishing Inc. This work is licensed under the Creative Commons Attribution International License (CC BY 4.0).

http://creativecommons.org/licenses/by/4.0/

\begin{abstract}
The purpose of this article is to explore brand value networks and transmission mechanism in sharing economy based on prosumption logic. This study used Charmaz's constructivist grounded theory to analyze the lectures and interviews, which come from founders and executives of Airbnb, Uber, Xiaozhu.com, and Didi. After coding analysis, we finally proposed a research model to explain the frame of brand value and showed the brand value transmission mechanism based on prosumption logic. In this article, we constructed that the frame of brand value based on prosumption logic consists of brand value, brand value net, and water wave effect. The water wave effect reveals the transmission mechanism of brand value under the logic of prosumption, which is not a chain transmission model, but a water wave mechanism. Overall, our results enrich the literature in the field of brand value in sharing economy.
\end{abstract}

\section{Keywords}

Sharing Economy, Prosumption, Brand Value, Value Network, Grounded Theory

\section{Introduction}

Sharing is a basic consumer behavior (Belk, 2010). Since the 21st century, the Web 2.0 and the network society have triggered social dramatic changes. In the Web 2.0 era, information technology makes it easy for people to share their views and experiences on the web, especially the user-generated web (eg. YouTube, Twitter, Facebook) (Ritzer and Jurgenson, 2010). The sharing economy-based on the prosumer's activity-is now reshaping how the economy is operated and has changed people's lifestyles with a resource evolution that brings about a brand-new approach to organize our economic lives. Behind 
sharing economy is a revolution in means of production. Through online platform, companies usually invite consumers to provide their own ideas and contributions. In the process of the cooperation between producers and consumers, consumption activities integrate with the production activities. Therefore, the role of consumers is blurring and the division between production and consumption is integrated (Cova et al., 2011). At the same time, "the hegemony of prosumers is the clearest" (Ritzer et al., 2012). As new producers, prosumers provide user-generated content online so as to form products (services) (Chandler and Chen, 2015). At the end of 2007, the global economic crisis led to a decline in consumption and production. Social drastic changes promote contemporary society away from the abnormal separation of consumption and production, ushering in the third wave of prosumption (Ritzer and Jurgenson, 2010). In 2006, Toffler predicted the coming of the era of prosumers that would pose a challenge for the existing society (Ritzer and Jurgenson, 2010).

At the end of 2007, after the global recession, the demand for frugal consumption increased dramatically. Sharing, an old prosumption behavior became more popular with the development and innovation of digital technology. The development of information and communications technologies (ICTs) alongside the growth of web 2.0 has enabled the rise of so-called "sharing economy": the peer-to-peer-based activity of obtaining, giving, or sharing the access to goods and services, coordinated through community-based online services (Hamari et al., 2016). And the prosumption is the prominent characteristic of sharing economy (Cohen and Muñoz, 2016). The emergence of sharing economy has stimulated more consumption through sharing underutilized assets (Botsman, 2013). Sharing economy not only enables us to collaboratively consume underutilized resources (Cho et al., 2019), but also enables individuals to engage in the process of production (Jaakkola and Alexander, 2014), even to co-create value together with providers (Vargo \& Lusch, 2011). Eventually, through sharing online platform, we transform the massive untapped resources to wealth and benefits.

In the Web2.0 era, the emergence of prosumption logic changes the research premise of brand value in sharing economy. Previous studies argued that brand value is mostly evaluated by consumers or enterprises and that-according to different evaluation subjects-brand value can be classified into three categories: the brand value based on consumers, the brand value based on the market and the brand value based on finance. Asker and Keller and other scholars believe that brand value is up to the consumer to decide, and most studies on marketing focus on the brand value based on consumers (Christodoulides \& de Chernatony, 2010). With the development of digital technology, the rise of prosumer capitalism represented by the sharing economy will fundamentally revolutionize the existing marketing theories, making the prosumer, not the consumer, the new evaluation subject of brand value. Although, there has been a great amount of research of brand value based on consumer (Tasci et al., 2018) or product 
(Huang and Sarigollu, 2014), a research of brand value based on prosumer is lacking. The brand value chain model of Keller and Lehmann (2003) illustrates brand value transmission mechanism from the consumer's perspective. With the advent of the digital age, the value chain theory is no longer applicable to analyzing multiple industries and identifying the source of value (Möller and Rajala, 2007). As the corporation of customers and producers under the impact of Web 2.0 , the traditional value chain will evolve into a value network. Besides, in sharing economy, the brand knowledge, brand experience, brand relationship quality, brand citizenship behavior and so on play a crucial role in the brand value network and the brand transmission mechanism will have a large change in view of prosumer. Therefore, it is significant to explore the brand value network based on prosumption logic and brand value transmission mechanism in sharing economy.

\section{Literature Review}

\subsection{Prosumption Logic}

In the past, the relationship between consumers and producers was seen as a relationship of value exchange (Bagozzi, 1975). The value chain of Porter (Porter, 2001) shows the merchandise purchased by the consumer experienced a series of steps from purchases to sales. Most experts focus on studying what consumers buy and ignore what consumers do, treating consumers as passive recipients rather than creative individuals, and separating consumption and production artificially (Xie et al., 2008). Marx \& Engels (1987) thought that the difference between consumers and producers is whether the value created is the value in exchange or use, that the producer manufactures goods in order to obtain value in exchange and the consumers buy goods in order to obtain the value in use, and that there is a dialectical relation of unit of opposites between producers and consumers (Marx and Engels, 1987).

Over the past two decades, experts have criticized the dichotomy of prosumption, and believe that production and consumption are inseparable (Pietrykowski, 2007; Ritzer and Jurgenson, 2010). In the opinion from Pietrykowski (2007), a clear division of production and consumption is not reasonable, and consumer identity occurs again and again through the consumption process, so the consumption also exists in the process of production. Consumption is a part of production (Curtin and Gaither, 2007). There are some experts who from the perspective of members of the organization show that the social roles of staff and customer are becoming invalid (Cardador and Prat, 2006), and discuss the inseparability of prosumption. Toffler \& Alvin (1981) use the "prosumer" to describe the role of consumer who changes from the value in exchange to value in use. Prosumption refers to a process in which people adapt, modify or transform the product, integrate personal creativity and product, involving a series of continuous activities of production and consumption (Toffler and Alvin, 1981). Tapscott and Williams (2007) analyze the difference of production and con- 
sumption with customer centralism. They point out that prosumption considers consumers as a part of a creative activity, and that customer centralism indicates companies provide basic options, which are further improved by customers, for example, the decision to purchase a new car. Xie et al. (2008) argue that prosumption is the process of value co-creation created by the individual and the seller, and ultimately produces the goods or services consumed by the individual. The whole production process is the consumption experience of the individual. This definition emphasizes that prosumption is not just the single purchase behavior, but the integration of physical and psychological activities, and emphasizes the social and psychological experience in the process of cooperation with the seller. Prosumption is not only the simple collection of production and consumption. Because the creation of experience in prosumption requires not only producers and consumers, but also participation and innovation (Seran and Izvercian, 2014).

At present, the widely recognized definition proposed by Ritzer \& Jurgenson (2010) is that prosumption is a series of continuous activities without any difference between production and consumption, and production and consumption are integrated rather than focusing on one or the other. The word of prosumer is composed of producer and consumer, which are the subject of the combination of producer and consumer. To sum up, this study believes that the prosumption logic is the premise of the integration of production and consumption, and the core is to create value, and the guiding logic of value creation management.

Under the environment of web 2.0, the phenomenon of prosumption has gradually attracted more and more attention. At present, through collecting and analyzing the literature in field of prosumption based on marketing discipline, our team found the research is mainly focused on three respects: prosumer and co-creation, prosumer and user-generated content (UGC), and prosumer and informational capital. In the respect of prosumer and co-creation, Cova \& Cova (2012) explained that the importance of prosumer and the development of consumer competencies in the process of value co-creation. And Candler \& Chen (2015) explained the prosumer motivations in service experiences. They described the relationship between prosumer and co-creation and have a lager influence on the research of prosumer. In the respect of prosumer and UGC, Morreale (2014) examined the prosumption of YouTube in consuming and sharing economic. And according to his research, we found the importance of UGC for platform brand and the role of prosumer in the process of value co-creation in sharing economic. In respect of prosumer and informational capital, Ritzer et al. (2012) explained the nature of capitalism in the age of the digital "prosumer" based on the analysis of production, consumption and prosumption. Prosumer capitalism shows that business firms engage consumers in value co-creation process without any compensation, whereas these "consumers" become the unpaid prosumers instead of low-paid commodified workers. Fur- 
thermore, compared with the low-paid commodified workers, prosumer capitalism increasingly prefer to exploit the largely unpaid prosumers (Ritzer and Jurgenson, 2010; Ritzer, 2015). The research on the field of prosumer and informational capital shows that the new business model of platform firms and the competitive advantages of prosumers in the age of digital information.

Web 2.0 provides users a broad platform which is used to publish personal opinions and generate content. And the platform organizations can advertise and sell the same user-generated contents (big data) to other marketing companies in order to gain more profit (Boone et al., 2019; Jimenez-Marquez et al. 2019). Obviously, the prosumption activities can bring great value to the enterprise, especially in collective consumption and actor engagement, because it is essential and reciprocal (Ma et al., 2019; So et al., 2018). Briefly speaking, due to the sharing platform, on the one hand, the business firms can gain more profits and competitive advantage though engaging prosumers to participant in the process of prosumption. On the other hand, the prosumers also can acquire more market share especially in the process of value co-creation (Cova \& Cova, 2012; Cova et al., 2015). In addition, in sharing economic, consumers are no longer passive recipients of value, but co-creators of value, which also shows the importance of prosumption logic in the process of value creation. However, how to create these values? How does it spread? How do the prosumption activities affect the brand value of enterprises? How does brand value spread under the logic of prosumption? These problems are worthy of our further study.

\subsection{Brand Value}

The study of brand theory can be divided into five stages, e.g. the unique selling proposition and brand image strategy (e.g. Ogilvy, 1963) from 1950s to 1960s; the theory of brand positioning from the 1970s to the 1980s (e.g. Ries \& Trout, 1981; Reeves, 1961), etc. Since the 1990s, brand research focuses on the components of brand elements (e.g. Aaker, 1991; Keller, 1993), and brand equity theory (e.g. Farquhar, 1989), etc. According to Anselmsson et al. (2007), the most influential definition of brand value since 1989 can be summarized into five aspects: 1) brand value is not so much the result of object indication as the result of consumer perception. 2) brand value is the global impression that value assists a brand. 3) brand value comes from brand naming, not simply the distribution of objects. 4) brand value is a correlation measure compared with reliable competitors. 5) brand value will undoubtedly affect the financial value of the brand.

The conceptual model of brand can be generally divided into three categories: first, the AKER model based on the enterprise perspective. Aker $(1991,1996)$ divides the discussion on brand assets into five aspects: brand awareness, brand loyalty, brand association, brand perceived quality and other exclusive brand assets. What is more, Aker (1996) to refine five dimensions, divided into 10 specific evaluation indicators: loyalty (satisfaction/loyalty, premium), brand recognition (quality cognition, popularity), brand association degree (value, brand 
personality, enterprise organization association), brand awareness, market situation (market prices and sales area, market share). Second, the CBBE model is studied from the perspective of consumers, which is that "customer-based on Brand Equity model” created by Keller (1993). Keller (1993) defines brand equity from a consumer perspective and discusses how to measure and manage brand equity. The CBBE model assumes that brand power exists in consumers' knowledge, feeling and experience, that is, brand power is the sum of all experiences that a brand left in consumers' mind over time. Third, the theory of brand value based on the perspective of prosumption. Chu \& Kim (2011) studied on value co-creation in the field of prosumption. They focus on the process of whether the prosumption behaviors influence each other. Toffler \& Alvin (1981) and Ritzer \& Jurgenson (2010) studied the conception of prosumer. Ritzer \& Jurgenson (2010) proposed an integrated model of production and consumption. Ritzer \& Jurgenson (2010), Xie et al. (2008) studied the connotation and form of prosumer behaviors in the context of Web 2.0, and the value of UGC in production-consumer activity, etc. (Tian et al., 2018).

Along with the development of the digital information technology and the emergence of sharing economy, the brand theory based on the perspective of producers or consumers is overturned by prosumption logic. The main role of brand value evaluation is no longer consumers but prosumer. Therefore, it is necessary to explore the frame of brand value network and the transmission mechanism based on the prosumption logic in sharing economy.

\subsection{Sharing Economy}

Ritzer et al. (2012) point out that the sharing economy is a typical type of prosumption. The essence of the sharing economy is prosumption. The sharing economy based on prosumption logic subverts the traditional industry and reshapes the world economic model, which attracts particular concern from academia, industry and government.

Why is Airbnb almost synonymous with the sharing economy but the traditional bed and breakfast are not a kind of the sharing economy? Why is the website ZBJ.com a kind of sharing economy but the traditional labor market not? The sharing economy is also known as the cooperative economy, the collaborative consumption, or the P2P economy. Botsman and Rogers (2010) mentioned that "In recent years, there have been some emerging enterprises whose business models have a common feature in which people provide and share the underutilized resources, using creative or innovative methods. They are a kind of the sharing economy or collaborative consumption".

Unlike the traditional relationship between producer and consumer in the traditional economic model, the core of the sharing economy is prosumption. Prosumption makes the sharing economy to have the five criteria, by which the sharing economy is different from the traditional economy. Unlike the purely monetized goods exchange, the sharing behavior blurs the social boundaries, 
generating and regenerating social relations. Unlike the sharing among relatives, neighbors and other acquaintances, the sharing on the Internet among the strangers is an important feature of the contemporary sharing economy. The sharing economy is based on the credibility mechanism created by crowd sourcing information to reduce the commercial cost of the sharing economy. The traditional commodity exchange is related to the permanent transfer of ownership and use rights, and the sharing economy is involved in the transfer of non-permanent rights of use. The participants in the modern sharing economy willingly share rather than being forced to share. In the vast majority of enterprises in the sharing economy, the profit model is to extract the commission for each single transaction, while the benefit is maximized in each transaction in the traditional business model (Schor and Fitzmaurice, 2015).

\section{Research Design}

\subsection{Method}

The grounded theory is recognized as the most scientific qualitative study methodology and an exploratory study methodology to generate a theoretical thinking. In this paper, The Charmaz's constructivist grounded theory is used to explore the frame of brand value network in the sharing economy. The research process (Charmaz, 2009) is demonstrated in Figure 1.

\subsection{Data Collection and Theoretical Sampling}

In this article, the discussion on the frame of brand value network should be based on the industry perspective rather than the prosumers' perspective. Due to the perspective of industry must cover the prosummers, the original material should be derived from the brand which is a bridge of the industry and the prosumers. First of all, the online brands in the sharing economy are chosen as the study object. At the same time, the author only discusses the platform brands in sharing economy rather than individual brands on the platform. Moreover, public lectures and interviews from founders and executives in these brands are collected as the original materials in the process of grounded research.

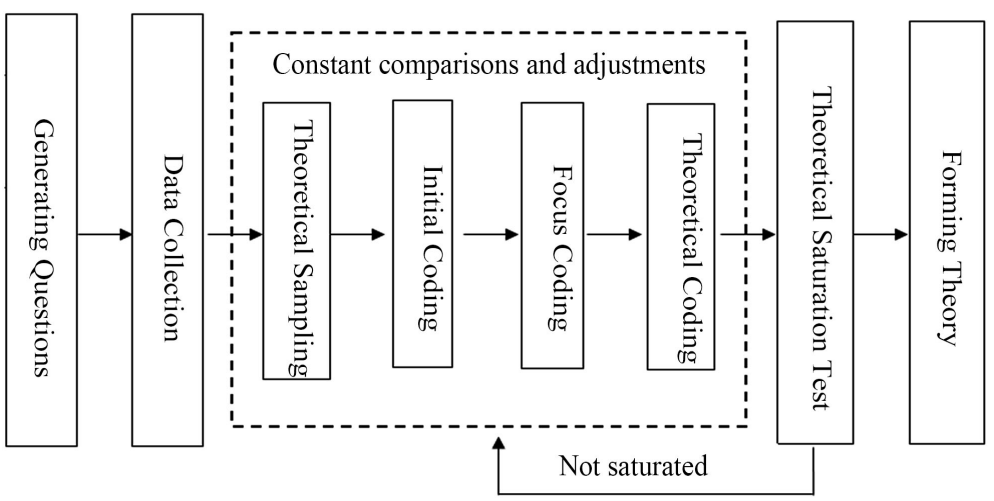

Figure 1. The process of Charmaz's constructivist grounded theory. 
At the beginning of the study, this paper selects the well-known Airbnb and Uber as the study object, and collects lectures and interviews of their founders and executives from website for qualitative research coding (the number of the lectures and interviews of Airbnb is 12, and Uber is 29). Although core concepts and categories gradually emerge, it is difficult for the samples to reach theoretical saturation in some categories. In order to solve this problem, this paper further selects lectures and interviews from founders and executives in Xiaozhu and Didi which are prosumption brands in China. Report of Sharing Economy Development in China (2016) points out that the domestic enterprises of China represented by Xiaozhu.com and Didi are promoting the development of the sharing economy in China. Therefore, it is reasonable to take Xiaozhu.com (the total number of materials is 34) and Didi (the total number of materials is 20) as the domestic samples. This paper collects the materials and makes comparisons constantly in the coding process until the theoretical saturation is obtained. Finally, we collected 95 lectures and interviews from different websites. And the original materials of a total of 300,000 words are selected from four brands in the sharing economy-Airbnb, Uber, Xiaozhu and Didi. The key information is illustrated in Table 1.

Table 1. Key informant's profile.

\begin{tabular}{|c|c|c|c|c|}
\hline Company & Name & Position & Date & Number \\
\hline \multirow[t]{4}{*}{ Airbnb } & Brian Chesky & Founder & 2015 & 5 \\
\hline & $\begin{array}{l}\text { Nathan } \\
\text { Blecharczyk }\end{array}$ & Founder & 2015 & 4 \\
\hline & Jason Bosinoff & Head of Growth & 2014 & 1 \\
\hline & Varsha Rao & Former Head of Global Operations & 2014-2015 & 2 \\
\hline \multirow[t]{5}{*}{ Uber } & Travis Kalanick & Founder and Chief Executive Officer & $2015-2016$ & 11 \\
\hline & Luo Gang & General Manager of South China & $2015-2016$ & 4 \\
\hline & Liu Zhen & Responsible person in strategy & $2015-2016$ & 10 \\
\hline & Zhang Yanqi & $\begin{array}{l}\text { General manager of North and South in } \\
\text { China }\end{array}$ & 2015 & 2 \\
\hline & Wang Ying & General manager of Central China & 2015 & 2 \\
\hline \multirow[t]{5}{*}{ Didi } & Cheng Wei & Founder and Chief Executive Offer & $2015-2016$ & 12 \\
\hline & Wang Gang & Angel investor & 2015 & 1 \\
\hline & Liu Qing & Chief Operating Officer & $2014-2015$ & 5 \\
\hline & Zhang Bo & Chief Technology Officer & 2015 & 1 \\
\hline & Zhu Jiang & Urban manager & 2014 & 1 \\
\hline \multirow[t]{3}{*}{ Xiaozhu.com } & Chen Chi & Founder & $2013-2016$ & 31 \\
\hline & Pan Caifu & Vice president & 2016 & 2 \\
\hline & Wang Liantao & Founder & 2013 & 1 \\
\hline
\end{tabular}


In this article, the original materials (about 220,000 words) from three brands, namely Airbnb, Uber and Didi, are used for the qualitative code analysis (initial coding, focus coding and theoretical coding) to form the frame of brand value based on prosumption logic. Then, the original materials (about 80,000 words) from Xiaozhu.com are used to test the theoretical saturation. The conclusions of this study are discussed and compared with the previous studies.

\section{Data Analysis}

\subsection{Opening Coding and Axial Coding}

First of all, this article applied to the analysis software of ATLAS 7 for initial coding. And according to the Charmaz's constructivist grounded theory, this article divided the data into different categories by means of verbatim coding and sentence coding, then defines these categories. Next, through summarizing the point of sentences and clarifying the vague parts, this paper extracted the connotative meaning. After, we constantly compared different data and found the holes in the data, then abandoned the unreasonable sentence. Finally, we required 851 initial codes from the original materials.

Secondly, we need to start the focus coding. Though continuously adjusting and comparing the original data and codes, we adopted initial codes which are the most important or have the highest frequency to integrate data and form focus coding. In focusing coding, by making repeated analysis and comparisons, this study extracted 60 core concepts, which are further abstracted into 41 categories and higher-level categories, including 19 sub-main categories, 3 main categories and 1 cor category. The specific categories and their relationships are shown in Figure 2.

\subsection{Theoretical Coding}

After the opening coding and axial coding, we believe that the core categories have been saturated. The theoretical sorting, diagramming, and integrating are provided to construct theory. At this stage, we carried out the theoretical construction based on the main categories, and constructed the brand value network based on prosumption logic. The typical relation structure of the main categories is shown in Table 2.

According to recommendations of Strauss and Corbin, this paper shows categories' relationships and the relationships between main categories in means of a drawing method (Charmaz, 2009). Based on our team research of brand value, this study built a brand value network based on prosumption logic, which consists of three parts: the frame of brand value based on prosumption logic, value co-creation for the brand and its stakeholders, and water wave effect. That is to say that the brand value network based on prosumption logic is a complete value growth and evolution system formed by the value co-creation of the brand and its stakeholders (especially prosumers), which interacts with the external environment. The details about the brand value network are shown in Figure 3. 
In sharing economy, at first, the brand value based on prosumption logic generates from the value co-creation between the platform brand and prosumers.

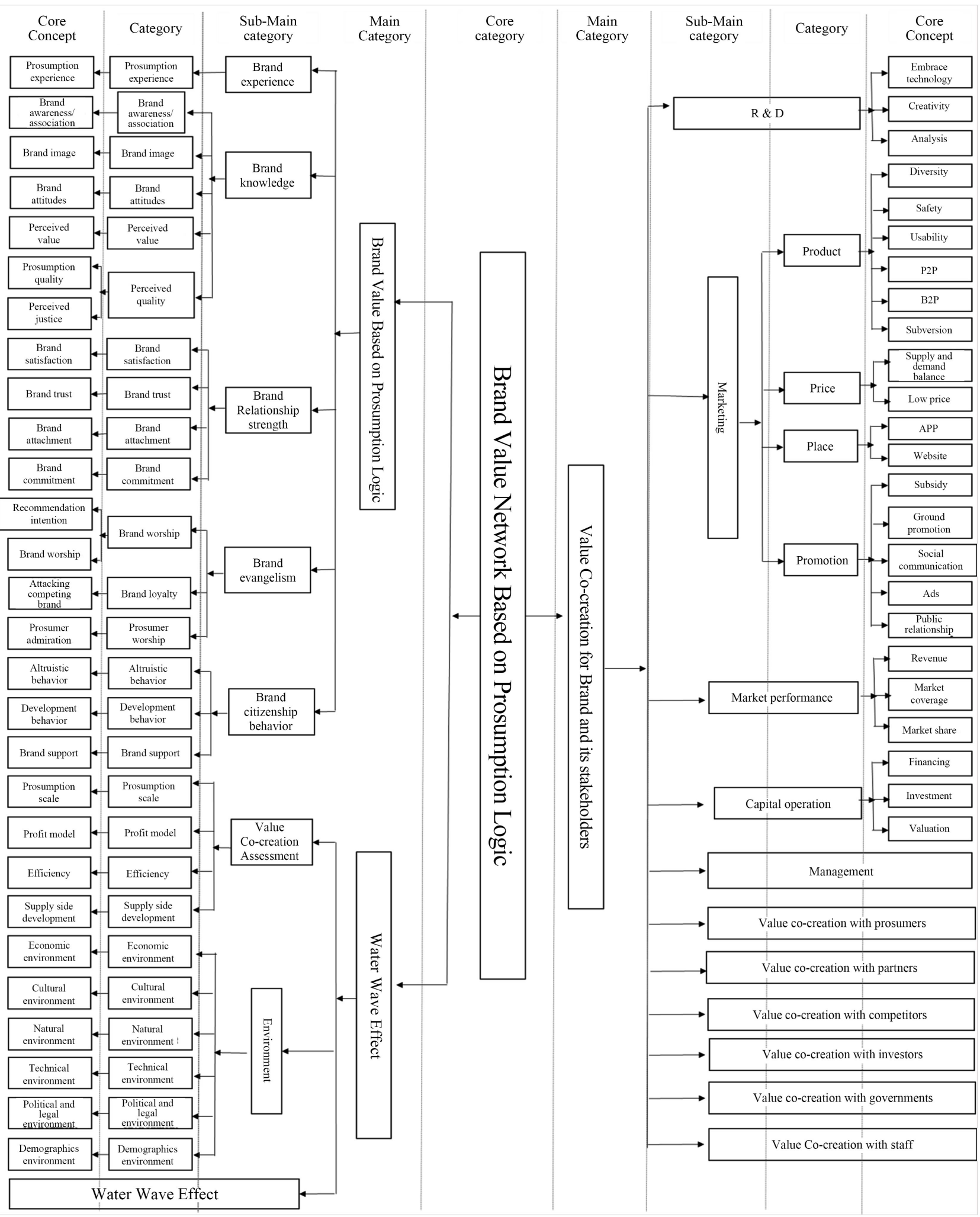

Figure 2. Categories' relationships. 


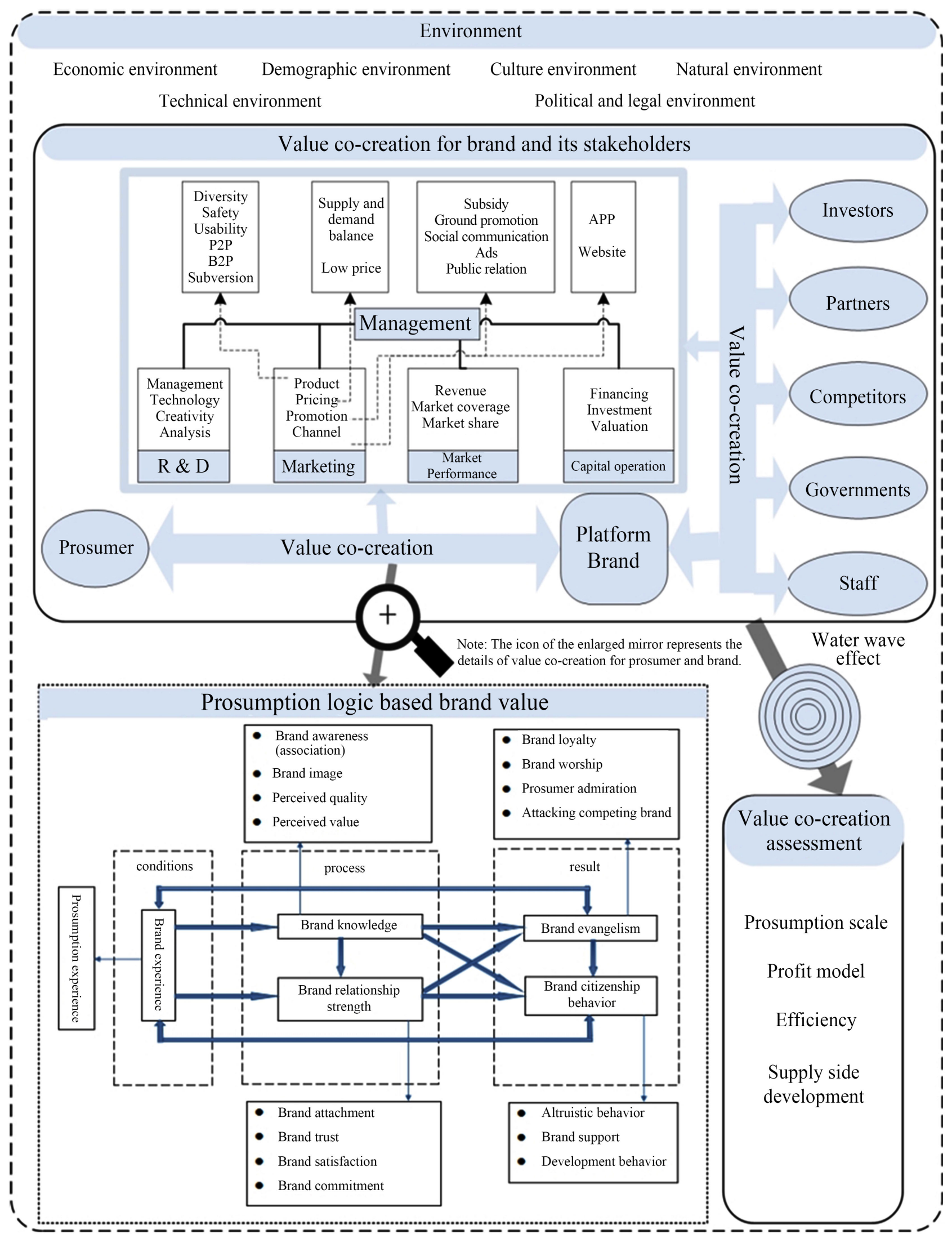

Figure 3. The brand value network based on prosumption logic. 
Table 2. Typical relational structure of the main categories.

Implication of typical relation structure
Typical relation structure:
Value co-creation is based on the prosumption
activities.

activities.

The brand and brand stakeholders (especially prosumers) co-create value together.

The value co-creation between the brand and stakeholders affects the brand value network based on prosumption loigc.

Value co-creation can be evaluated from four aspects: profit model, prosumption scale, efficiency and supply side development.

There is a water wave effect in the process of value co-creation and brand value transmission. The interaction between the brand and brand stakeholders (especially prosumers) produces the value which continuously enlarges, passes and spreads like the water wave when a stone is thrown into the water.

\section{Typical relation structure:}

The brand may be affected by economy, culture, politics, laws, demographics, science and technology, and natural environment. The brand has an active influence on the environment.

Typical relation structure:

The brand profit may be affected by economy, culture, politics, laws, demographics, science and technology, and natural environment. The brand profit has an active role in the environment.

\section{Representative quotations from interviewee}

Value co-creation

brand $\leftarrow \rightarrow$ brand stakeholders

A guest sent a message that she would stay this weekend. Chen Chi told her, "I shall go out this weekend, so you can open the password lock and lodge."

If you become our landlord, then we can do a lot of work for you. According to Chen Chi, the staff of Xiaozhu can give a lot of suggestions by discussions with the landlord, for example, how to host a stranger, how to get along with a stranger, and how to show your care.

Citizens' behavior has not been trained, so the obstacles still exist. There are legal issues. If these issues are not solved, many landlords still will face obstacles.

Didi develops from 800 thousand yuan to 100 billion in three years, becoming the world's largest mobile travel platform. It is a typical representative in the sharing economy, the Internet innovation and the supply side reform.

Paul Graham once said, "(Let us) do a little thing which seems to be insignificant, but can promote the growth.”

We started to be a landlord. And it was very difficult ... but in today, in some major cities, more landlords can actually know our business model from a lot of channels, and understand how the previous landlords to do this thing, what the experience is, and how to solve the problem.

\section{Brand $\leftarrow \rightarrow$ environment}

After two months of trial run, we have reduced the carbon emissions by hundreds of tons. Through the use of real name, Xiaozhu.com can promote the establishment of the entire social credit system.

\section{Environment $\leftarrow \rightarrow$ brand stakeholders}

This Wednesday, thousands of London taxi drivers boycotted Uber in the streets ... "The taxi industry is trying to maintain a monopoly position that is set up by the local government, and they hope to reduce the competition."

And it is the reason for the value growth in sharing economy, and it is the basic unit of the brand value network based on prosumption logic. Secondly, the brand value net based on prosumption logic generates from the value co-creation between the platform brand and its stakeholders. And it is a part of the brand value network based on prosumption logic. Then, due to the wave effect in the 
process of the brand value transmission, the value co-creation between the platform brand and its stakeholders (especially prosumers) continuously enlarges, passes and spreads like the water wave when a stone is thrown into the water. Finally, it exerts a large external effect on individual, organization and environment within the value network. This value co-creation can be constrained by the environment. The brand and its stakeholders are affected by the environment and play a dynamic role in the environment. The environment includes economic environment, cultural environment, political and legal environment, demographic environment, technology environment, and natural environment. At last, the brand value network based on prosumption logic is formed. Besides, it is worth noting that the brand value no longer spreads in a linear way, but in a wave way.

\subsection{Theoretical Saturation Test}

In this article, the conceptual model is subject to the saturation test using original materials from Xiaozhu.com. In the stages of initial coding and focus coding, no category occurred. In the stage of theoretical coding, no new logical relation or clue occurred. The results of qualitative coding showed that the brand value network based on prosumption logic is theoretically saturated.

\section{Discussions}

The brand value chain of Keller \& Lehmann (2003) comprehensively proposed the process of brand value creation under the goods-dominant logic. In the brand value chain, corporate marketing activities affect consumers as a starting point. And in turn, it affects the brand's performance in the market. Ultimately, the brand value is measured through the financial approach. The value chain theory is a common tool for analyzing competitive advantages in enterprises and their competitors. And it is suitable to analyse the value creation of traditional industries (especially traditional manufacturing), but the linear model of value chain theory provides a narrow view. It focuses on individual enterprises or upstream and downstream enterprises involved in the value chain, instead of alliances, competitors, partners and other business members (see Lu et al., 2012).

In sharing economy, the brand value is created by the brand and its stakeholders (consumers, investors, partners, competitors, governments and employees). The brand value transmits through the brand value network based on prosumption logic and by means of a wave effect, not through a linear model of the brand value chain. The specific analysis is following here.

\subsection{The Brand Value Network Based on Prosumption Logic}

The basis of brand value network based on prosumption logic is based on economic theory, rather than transaction cost theory. The value network is a value creation model driven by information technology under the knowledge economy environment. This article suggests that the value network theory is 
suitable for discussing the creation of brand value based on the prosumption logic in sharing economy. We find that the frame of brand value network focuses on the value co-creation of the brand and its stakeholders, and covers the key elements of the value network: ideas (business purpose and strategy, execution factors), components (market, information and communication facilities, financial investment and resources), background (external environment, which is generally referred to government, economic and social structure) (Mariotti, 2002). The brand value network based on prosumption logic integrates the internal and external resources to inspire the innovative cooperation with stakeholders in $\mathrm{R} \& \mathrm{D}$, procurement, production, sale and so forth. It promotes the growth of prosumers and other stakeholders, and plays a dynamic role in the external environment. Then it also promotes the growth of the brand itself. Therefore, it meets four aspects of the release of the value network (Sanford and Taylor, 2008).

Under the prosumption logic, the model of the brand value network is based on previous value network theories, but it has the following differences.

1) Under the prosumption logic, the virtual value growth is the main force of brand value growth. Previous studies suggest that information is the source of value growth in the digital age. The content of the information, especially the user-generated content (UGC), reflects the brand value. The information passes in the virtual value chain, and then links into a huge value network, finally, the brand value network based on prosumption logic is formed.

Under the goods-dominant logic, the brand value transmission mechanism is the brand value chain theory which is developed on the basis of the value chain theory. The value chain that composed of continuous activities such as enterprise R \& D, purchasing, production and sales is mainly involved in tangible logistics, capital flow, and human capital. And the brand value chain also has a flow of information, but the information is only the auxiliary element in value-adding activities.

Under the prosumption logic, the brand value chain consists of a tangible offline value stream and an invisible online value stream. In the offline logistics, capital flow and human capital are accompanied by a huge amount of information flow. This huge amount of information flow integrates the development, procurement, production, sales and finance so forth as a whole. In sharing economy, the brand experiences a series of activities including $\mathrm{R} \& \mathrm{D}$, marketing, capital operation and so forth, and constitutes an offline tangible value stream. At the same time, it also experiences a series of nonlinear activities including information collection, analysis and so forth. Thus it constitutes an online virtual value stream. Besides, each link of the tangible value stream combines the virtual value stream, for example, data analysis in the $\mathrm{R} \& \mathrm{D}$ activities.

2) The brand value network based on prosumption logic reveals the water wave effect of value transmission. When the brand co-create value with its stakeholders, especially prosumers, each interaction is like throwing stone into 
the pond to form water waves (i.e., adding value) which will make new waves. The value co-creation of the brand and prosumers stimulates the growth of the brand value at $\mathrm{R} \& \mathrm{D}$ stage, and transmits the value at the marketing stage. The brand company and prosumers continue to interact at marketing stage, and make the brand value continuously accumulate, and so on. Therefore, the brand value transmission has a water wave effect, which brings a very rapid value-growth in the entire brand value network based on prosumption logic. Thus we can explain why the brands in the sharing economy can achieve a rapid success, for example, Airbnb, Uber, but also can be easy to close down, for example, some of $\mathrm{P} 2 \mathrm{P}$ platforms.

\subsection{The Restructure of the Brand Value Based on Prosumption Logic}

The previous study suggests that the brand value under the goods-dominant logic is from the consumer (i.e., brand value based on consumer) and brings the value for shareholders. With the transformation from the consumer to the prosumer, the brand value based on prosumption logic should be inherited and innovated based on the consumer-based brand value. Brand awareness/association, brand image, perceived quality, brand attitude and perceived value in the sharing economy model are condensed into a higher level of the brand knowledge. Brand attachment, brand trust, brand satisfaction and brand commitment are condensed into a higher level of the brand relationship strength. What's more, brand worship, brand loyalty and prosumer worship constitute a higher level of the brand evangelism. Importantly, in sharing economy, the altruistic behaviors, development behaviors, and brand support appear in prosumers's activities. These behaviors are condensed into the brand citizenship behavior. Therefore, based on prosumption logic in sharing economy, the brand value model is composed of five dimensions: brand experience, brand knowledge, brand relationship strength, brand evangelism, and brand citizenship behavior.

\subsection{Value Co-Creation for the Brand and Its Stakeholders}

In sharing economy, the value co-creation for the brand and its stakeholders can be evaluated from the four dimensions: prosumption scale, profit model, efficiency and supply side development, this is also known as the value co-creation assessment. The brand' stakeholders under the prosumption logic are made up of producers, governments, competitors, partners, investors and employees.

In terms of the value co-creation for the brand and its stakeholders, this paper reveals the following findings.

1) In sharing economy, the approach of value creation changes. Under the goods-dominant logic, the production and consumption are separated from each other. In the stage of production, the enterprise is the leader of value creation, and the consumer is the participant (Ferreira et al., 2015). In the stage of consumption, under the goods-dominant logic, the customer is the leader of value creation, and the enterprise is the participant. However, in the era of prosumption, 
production and consumption are not separated from each other. Prosumers participate in R \& D, marketing, market performance and capital operation so forth. They interact with the brands to continuously enlarge the brand value. Besides, the platform brands have recognized the important role of stakeholders (investors, partners, competitors, governments and employees) in the process of value creation. Under the prosumption logic, the value co-creators are brands, prosumers, and brand stakeholders.

2) In sharing economy, the perspective of brand value assessment has changed, including four dimensions: prosumption scale, profit model, efficiency and supply side development. Under the goods-dominant logic, the value co-creation for the brand and the customer is referred to the enjoyable value and function value. Therefore, the value co-creation of brand and customers is assessed and measured from the customer's view, including the following dimensions: cocreation (including knowledge, equity and interaction) and value in use (including experience, customization, and relationship) and so forth. However, the following points are neglected: the role of brand stakeholders in the value cocreation and the value co-creation assessment from the organizational perspective. Because the value is not only co-created by brands and prosumers, but also by stakeholders (investors, partners, competitors, governments and employees). In addition, this study finds that value co-creation is also affected by the environment. In sharing economy, three dimensions of value co-creation assessment (i.e., prosumption scale, profit model, and efficiency) reflect the results of cyclical interaction among the prosumers, brand and its stakeholders. And the supply side development focuses on the contributes of prosumers in the market supply.

3) In sharing economy model, the categories of value co-creation for the brand and its stakeholders are broader than those for the brand and consumers. When the original materials used to extract the brand value are compared with the value co-creating scale under the goods-dominant logic (Ranjan and Read, 2016), the result shows that the categories of the previous scale are narrower. The previous scale includes the dimensions for the brand value based on prosumption logic: brand experience, brand commitment, brand attachment, perceived value, perceived quality, brand satisfaction, brand loyalty. But the following dimensions are not measured: brand awareness/association, brand image, brand trust and brand attitude.

\section{Conclusion}

This paper uses Charmaz constructivist grounded theory to construct the brand value network based on prosumption logic in sharing economy. The brand value network based on prosumption logic consists of three dimensions: the brand value based on prosumption logic, value co-creation for the brand and its stakeholders, and water wave effect. The brand value network is related to the existing concept, but this paper extends boundaries and connotations of the existing concept, and highlights the new features of the existing concept in the sharing 
economy model.

The frame of brand value offers three practical implications. Firstly, it provides conceptual insights into how the brand and the stakeholders co-create value based on prosumption logic. Therefore, more importance should be emphasized for the web2.0 platform brands on the stakeholders as prosumers. In sharing economy, the subject of evaluating brand value is no longer just customer, but prosumers. What prosumers do creates the brand, so prosumers represent the brand. Secondly, the study constructs the brand value model which includes five dimensions-brand experience, brand knowledge, brand relationship strength, brand evangelism, and brand citizenship behavior. Based on this model, the brands could promote the brand value by stimulating the brand evangelism and the brand citizenship behavior. As two highly productive dimensions, brand evangelism and brand citizenship behavior could stimulate the brand experience of others while inspiring prosumption activities. Through attracting other consumers to gather around the brand and create prosumption activities, brand evangelism and brand citizenship behavior promote a virtuous circle which plays a very important role in brand profit under the logic of prosumption. Thirdly, the water wave effect reveals the transmission mechanism of brand value under the logic of prosumption, which is not a chain transmission model, but a water wave mechanism. Web2.0 platform brands should pay more attention to the growth of brand value in the marketing stage. The brand value transmission has a water wave effect, which brings a very rapid value-growth in the marketing stage.

The results of this article fill the gap in the study of brand value transmission mechanism in sharing economy, which provides a theoretical framework for the further empirical study. The authors hold a rigorous attitude to do the grounded theory study, but due to the limitation in the theoretical sensitivity, conclusions are subjective to a certain extent. And due to the limitation in study conditions, the research has lasted a long time since the original materials were collected. In addition, there is a lack of in-depth interviews with brand founders and executives. Therefore, some limitations exist in this study.

\section{Conflicts of Interest}

The authors declare no conflicts of interest regarding the publication of this paper.

\section{References}

Aaker, D. A. (1991). Managing Brand Equity. New York: Free Press.

Aaker, D. A. (1996). Measuring Brand Equity across Products and Markets. California Management Review, 38, 102-120. https://doi.org/10.2307/41165845

Anselmsson, J., Johansson, U., \& Persson, N. (2007). Understanding Price Premium for Grocery Products: A Conceptual Model of Customer-Based Brand Equity. Journal of Product \& Brand Management, 16, 401-414. 
https://doi.org/10.1108/10610420710823762

Bagozzi, R. P. (1975). Marketing as Exchange. The Journal of Marketing, 39, 32-39. https://doi.org/10.1177/002224297503900405

Belk, R. (2010). Sharing. Journal of Consumer Research, 36, 715-734. https://doi.org/10.1086/612649

Boone, T. et al. (2019). Forecasting Sales in the Supply Chain: Consumer Analytics in the Big Data Era. International Journal of Forecasting, 35, 170-180.

https://doi.org/10.1016/j.ijforecast.2018.09.003

Botsman, R. (2013). The Sharing Economy Lacks A Shared Definition. Fast Company. https://www.fastcompany.com/3022028/the-sharing-economy-lacks-a-shared-definiti

Botsman, R., \& Rogers, R. (2010). Beyond Zipcar: Collaborative Consumption. Harvard Business Review, 88,30 .

Cardador, M. T., \& Pratt, M. G. (2006). Identification Management and Its Bases: Bridging Management and Marketing Perspectives through a Focus on Affiliation Dimensions. Journal of the Academy of Marketing Science, 34, 174-184. https://doi.org/10.1177/0092070305284984

Chandler, J., \& Chen, S. (2015). Prosumer Motivations in Service Experiences. Journal of Service Theory and Practice, 25, 220-239. https://doi.org/10.1108/JSTP-09-2013-0195

Charmaz, K. (2009). Construction of Grounded Theory: A Guide to Qualitative Analysis. Chongqing: Chongqing University Press.

Cho, S., Park, C., \& Kim, J. (2019). Leveraging Consumption Intention with Identity Information on Sharing Economy Platforms. Journal of Computer Information Systems, 59, 178-187. https://doi.org/10.1080/08874417.2017.1326295

Christodoulides, G., \& de Chernatony, L. (2010). Consumer-Based Brand Equity Conceptualization and Measurement. International Journal of Market Research, 52, 43-66. https://doi.org/10.2501/S1470785310201053

Chu, S.-C., \& Kim, Y.-J. (2011). Determinants of Consumer Engagement in Electronic Word of Mouth (EWOM) in Social Networking Sites. International Journal of Advertising, 30, 47-75. https://doi.org/10.2501/IJA-30-1-047-075

Cohen, B., \& Muñoz, P. (2016). Sharing Cities and Sustainable Consumption and Production: Towards an Integrated Framework. Journal of Cleaner Production, 134, 87-97. https://doi.org/10.1016/j.jclepro.2015.07.133

Cova, B., \& Cova, V. V. (2012). On the Road to Prosumption: Marketing Discourse and the Development of Consumer Competencies. Consumption Markets \& Culture, 15, 149-168. https://doi.org/10.1080/10253866.2012.654956

Cova, B., Dalli, D., \& Zwick, D. (2011). Critical Perspectives on Consumers' Role as "Producers": Broadening the Debate on Value Co-Creation in Marketing Processes. Marketing Theory, 11, 231-241. https://doi.org/10.1177/1470593111408171

Cova, B., Pace, S., \& Skalen, P. (2015). Brand Volunteering: Value Co-Creation with Unpaid Consumers. Marketing Theory, 15, 465-485.

https://doi.org/10.1177/1470593115568919

Curtin, P. A., \& Gaither, T. K. (2007). International Public Relations: Negotiating Culture, Identity, and Power. Thousand Oaks, CA: SAGE Knowledge.

Farquhar, P. H. (1989). Managing Brand Equity. Marketing Research, No. 30, 24-33.

Ferreira, J. J., Fernandes, C. I., Alves, H., \& Raposo, M. L. (2015). Drivers of Innovation Strategies: Testing the Tidd and Bessant (2009) Model. Journal of Business Research, 68, 1395-1403. https://doi.org/10.1016/j.jbusres.2015.01.021 
Hamari, J., Sjoklint, M., \& Ukkonen, A. (2016). The Sharing Economy: Why People Participate in Collaborative Consumption. Journal of the Association for Information Science and Technology, 67, 2047-2059. https://doi.org/10.1002/asi.23552

Huang, R., \& Sarigollu, E. (2014). Assessment of Brand Equity Measures. International Journal of Market Research, 56, 783-806. https://doi.org/10.2501/IJMR-2014-037

Jaakkola, E., \& Alexander, M. (2014). The Role of Customer Engagement Behavior in Value Co-Creation: A Service System Perspective. Journal of Service Research, 17, 247-261. https://doi.org/10.1177/1094670514529187

Jimenez-Marquez, J. L. et al. (2019). Towards a Big Data Framework for Analyzing Social Media Content. International Journal of Information Management, 44, 1-12. https://doi.org/10.1016/j.ijinfomgt.2018.09.003

Keller, K. L. (1993). Conceptualizing, Measuring, and Managing Customer-Based Brand Equity. Journal of Marketing, 57, 1-22. https://doi.org/10.1177/002224299305700101

Keller, K. L., \& Lehmann, D. R. (2003). How Do Brands Create Value? Marketing Management, 12, 26-31.

Lu, T. H., Zhou, Y. J., \& He, Y. (2012). Origin of Value Network Research and Fusion Effect Analysis. Foreign Economics \& Management, 34, 65-73.

Ma, Y. et al. (2019). Value Co-Creation for Sustainable Consumption and Production in the Sharing Economy in China. Journal of Cleaner Production, 208, 1148-1158.

https://doi.org/10.1016/j.jclepro.2018.10.135

Mariotti, J. L. (2002). The Value Network. Executive Excellence, 19, 18. https://doi.org/10.1007/978-3-322-89834-0_4

Marx, K., \& Engels, F. (1987). Karl Marx Frederick Engels: Collected Works (Vol. 28, pp. 1857-1861). New York: International Pub.

Möller, K., \& Rajala, A. (2007). Rise of Strategic Nets-New Modes of Value Creation. Industrial Marketing Management, 36, 895-908.

https://doi.org/10.1016/j.indmarman.2007.05.016

Morreale, J. (2014). From Homemade to Store Bought: Annoying Orange and the Professionalization of YouTube. Journal of Consumer Culture, 14, 113-128.

https://doi.org/10.1177/1469540513505608

Ogilvy, D. (1963). Confessions of an Advertising Man. London: Southbank Publishing.

Pietrykowski, B. (2007). Exploring New Directions for Research in the Radical Political Economy of Consumption. Review of Radical Political Economics, 39, 257-283. https://doi.org/10.1177/0486613407302487

Porter, M. E. (2001). The Value Chain and Competitive Advantage. In Understanding Business: Processes (pp. 50-66). New York: The Free Press.

Ranjan, K. R., \& Read, S. (2016). Value Co-Creation: Concept and Measurement. Journal of the Academy of Marketing Science, 44, 290-315. https://doi.org/10.1007/s11747-014-0397-2

Reeves, R. (1961). Reality in Advertising. New York: Alfred A.

Ries, A., \& Trout, J. (1981). Positioning: The Battle for Your Mind. New York: McGraw-Hill.

Ritzer, G., \& Jurgenson, N. (2010). Production. Consumption. Prosumption The Nature of Capitalism in the Age of the Digital 'Prosumer'. Journal of Consumer Culture, 10, 13-36. https://doi.org/10.1177/1469540509354673

Ritzer, G., Dean, P., \& Jurgenson, N. (2012). The Coming of Age of the Prosumer Introduction. American Behavioral Scientist, 56, 379-398.

https://doi.org/10.1177/0002764211429368 
Ritzer. G. (2015). The "New" World of Prosumption: Evolution. "Return of the Same." or Revolution? Sociological Forum, 30, 1-17. https://doi.org/10.1111/socf.12142

Sanford, L. S., \& Taylor, D. (2008). Open Growth: Business Trends: From Value Chains to Value Networks. London: Oriental Press.

Schor, J. B., \& Fitzmaurice, C. J. (2015). Collaborating and Connecting: The Emergence of the Sharing Economy. Handbook of Research on Sustainable Consumption, 410, 26. https://doi.org/10.4337/9781783471270.00039

Seran, S., \& Izvercian, M. (2014). Prosumer Engagement in Innovation Strategies: The Prosumer Creativity and Focus Model. Management Decision, 52, 1968-1980. https://doi.org/10.1108/MD-06-2013-0347

So, K. K. F., Oh, H., \& Min, S. (2018). Motivations and Constraints of Airbnb Consumers: Findings from a Mixed-Methods Approach. Tourism Management, 67, 224-236. https://doi.org/10.1016/j.tourman.2018.01.009

Tapscott, D., \& Williams, A. D. (2007). Wikinomics. Beijing: China Youth Publishing House.

Tasci, A. D. A., Hahm, J., \& Breiter-Terry, D. (2018). Consumer-Based Brand Equity of a Destination for Sport Tourists versus Non-Sport Tourists. Journal of Vacation Marketing, 24, 62-78. https://doi.org/10.1177/1356766716679485

Tian, J. M., Shen, L., \& Chen, Y. (2018). Research on Brand Value Co-Creation and Strategy of Platform Enterprises in the Context of Network Sharing: From the Perspective of Customer Production and Consumption. Modern Economic Research, 127-132.

Toffler, A., \& Alvin, T. (1981). The Third Wave. New York: Bantam Books.

Vargo, S. L., \& Lusch, R. F. (2011). It's All B2B ... and Beyond: Toward a Systems Perspective of the Market. Industrial Marketing Management, 40, 181-187.

https://doi.org/10.1016/j.indmarman.2010.06.026

Xie, C., Bagozzi, R. P., \& Troye, S. V. (2008). Trying to Prosume: Toward a Theory of Consumers as Co-Creators of Value. Journal of the Academy of Marketing Science, 36, 109-122. https://doi.org/10.1007/s11747-007-0060-2 